\title{
Alternative Strategies for the Treatment of Classical Congenital Adrenal Hyperplasia: Pitfalls and Promises
}

\author{
Karen J. Loechner, ${ }^{1}$ James T. McLaughlin, ${ }^{2}$ and Ali S. Calikoglu ${ }^{1}$ \\ ${ }^{1}$ Division of Pediatric Endocrinology, Department of Pediatrics, University of North Carolina, CB\#7039, \\ 3341 MBRB, Chapel Hill, NC 27599-703, USA \\ ${ }^{2}$ Department of Pharmacology, University of North Carolina, Chapel Hill, NC 27599-703, USA
}

Correspondence should be addressed to Ali S. Calikoglu, asc@med.unc.edu

Received 9 April 2010; Accepted 11 May 2010

Academic Editor: Peter Allen Lee

Copyright (C) 2010 Karen J. Loechner et al. This is an open access article distributed under the Creative Commons Attribution License, which permits unrestricted use, distribution, and reproduction in any medium, provided the original work is properly cited.

Despite decades of different treatment algorithms, the management of congenital adrenal hyperplasia (CAH) remains clinically challenging. This is due to the inherent difficulty of suppressing adrenal androgen production using near physiological dosing of glucocorticoids (GC). As a result, alternating cycles of androgen versus GC excess can occur and may lead to short stature, obesity, virilization, and alterations in puberty. Novel therapeutic alternatives, including new and more physiological means of GC delivery, inhibitors at the level of CRH or ACTH secretion and/or action, as well as "rescue strategies", such as GnRH analogs, antiandrogens, aromatase inhibitors, and estrogen receptor blockers, are available many of these agents, however, still require active investigation in CAH. Bilateral adrenalectomy is effective but it is also still an experimental approach. Gene therapy and stem cells, to provide functional adrenal cortical tissue, are at preclinical stage but provide exciting avenues for a potential cure for $\mathrm{CAH}$.

\section{Introduction}

Appropriate treatment of children with congenital adrenal hyperplasia $(\mathrm{CAH})$ is challenging because it requires the simultaneous and continuous control of a number of physiologic mechanisms. The molecular defect, usually in the enzyme 21-hydroxylase $(21-\mathrm{OH})$, leads to a decreased production of cortisol that removes the normal negative feedback to pituitary corticotrophs $[1,2]$. Consequently, adrenocorticotropic hormone (ACTH) secretion is increased and drives the shunting of cortisol precursors to androgen synthetic pathways [3]. To control $\mathrm{CAH}$, therefore, it is necessary both to adequately replace glucocorticoids (and mineralocorticoids in salt-wasting forms) and to prevent the production of excess androgens.

Adequate control of CAH requires life-long glucocorticoid (GC) replacement sufficient to maintain adrenal androgen suppression. Determining the "optimal level" of GC replacement, however, can be elusive. Undertreatment leads to adrenal insufficiency and androgen excess, while overtreatment leads to obesity, iatrogenic Cushing's syndrome, and osteoporosis [4-10]. Both under- and over-treatment of CAH can result in diminished adult height [11-14]. The final effect on bone age (BA) maturation will reflect the integrated effect of GCs and adrenal androgens over time, especially in the prepubertal child.

We present an overview of new/potential treatment strategies aimed at improving the outcome in patients with $\mathrm{CAH}$. Included are strategies, such as $\mathrm{GnRH}$ analogs, antiandrogens, and aromatase inhibitors, for which there are clinical studies completed and/or ongoing to support their use in CAH. For other approaches, such as bilateral adrenalectomy and circadian hydrocortisone treatment, the treatment strategies have already been implemented in the clinical arena albeit in a small number of cases, but formal trials are lacking. Finally, we have included several regimens that have been utilized in other conditions and extrapolated for use in $\mathrm{CAH}$. 


\section{Glucocorticoid-Sparing Strategies}

2.1. Corticotropin Releasing Hormone (CRH) Antagonists. Corticotropin releasing hormone $(\mathrm{CRH})$ is the primary trigger for ACTH release from pituitary corticotrophs, and thus, modulation of $\mathrm{CRH}$ actions offers an opportunity to dampen ACTH release. More specifically, inhibition at this higher level in the HPA (hypothalamic-pituitary axis) would be expected to result in a decrease in ACTH release. Inhibition of both $\mathrm{CRH}$ and $\mathrm{ACTH}$, in turn, could permit lower GC requirements to maintain adrenal suppression while at the same time providing adequate replacement $[15,16]$. Preclinical studies in rodents demonstrate that the $\mathrm{CRH}$ antagonist, antalarmin, blocks $\mathrm{CRH} 1$ receptor-induced increases both in adrenal size and behavioral responses $[17,18]$. CRH analogues with more prolonged action such as astressin inhibit ACTH release [19], and alpha-helical CRF 9-41 reduces measures of stress in a sheep [20]. Trials using CRH (1) receptor antagonists in humans showed a decrease in CRH-associated signs of anxiety and depression. However, since the aforementioned studies in sheep and humans have not been clearly associated with decreases in $\mathrm{CRH}$-induced ACTH release and/or cortisol levels, the direct clinical applicability of $\mathrm{CRH}$ antagonists to $\mathrm{CAH}$ remains unclear $[20,21]$.

\subsection{Strategies Directly Targeting ACTH Action/Secretion.} Inhibition of either ACTH secretion or action, that is, targeting the next level of the HPA axis, represents another coherent strategy. The identification of selective melanocortin receptor subtypes (e.g., MC2-R for ACTH in the adrenal cortex) opens an avenue to blunt ACTH action at the adrenal gland and in turn reduce androgen production [2224]. Again, this approach could lower GC dosing with the goal of a more physiologic range, such as that used in Addison's Disease $\left(8-10 \mathrm{mg} / \mathrm{m}^{2} /\right.$ day; $\left.[25,26]\right)$ rather than the "suppressive" regimens $\left(12-15 \mathrm{mg} / \mathrm{m}^{2} /\right.$ day after infancy; [27]) usually required for CAH. Preclinical and clinical trials are needed to ascertain the safety and efficacy of ACTH receptor antagonists.

Blockade of ACTH release is another approach under investigation. In vitro studies demonstrated that $\mathrm{ACTH}$ release from corticotrophs is uniquely coupled to the dihydropyridine-sensitive subclass of voltage-dependent calcium channels, such as nifedipine or amlodipine, that are typically used to treat hypertension [28-30]. Clinical trials in Cushing's disease (another state of ACTH excess) reported acute decreases in ACTH levels with calcium channel blockers [31]. Amlodipine is a long-acting antagonist of DHP calcium channels that has been approved for pediatric hypertension, and it permits accurate daily dosing using a liquid suspension. We recently completed a placebo-controlled cross-over clinical trial in 13 children with either simple virilizing (SV) or salt wasting (SW) CAH (ages 6-12 years of age). We have found that addition of amlodipine $(0.1 \mathrm{mg} / \mathrm{kg}$ daily bedtime dosing) can attenuate ACTH levels in children with CAH ([32]; Loechner, unpublished observation). A mild elevation in heart rate was observed in $2 / 13$ children during change in position, but this was not associated with a drop in blood pressure nor clinical symptoms with the exception of one child who exhibited mild symptoms of postural hypotension. It is noteworthy that this child had a SW $\mathrm{CAH}$, suggesting that this approach may not be appropriate in such children. These data, however, suggest that the addition of the calcium channel antagonist, amlodipine, to $\mathrm{CAH}$ treatment regimen may be a safe and helpful adjuvant therapy in, at least, SV CAH. Longitudinal study is indicated to assess both effects of calcium channel blockade on longterm GC dosing, final adult height, and bone density.

Other potential agents to decrease ACTH secretion include cyproheptadine (a serotonin receptor antagonist), cabergoline (a dopamine agonist), and valproic acid (a GABA reuptake inhibitor). Each has been used with limited success in the treatment of Cushing's disease and Nelson's syndrome $[33,34]$, but their efficacy in the management of $\mathrm{CAH}$ remains to be studied.

\section{Glucocorticoid-Delivery Strategies}

\subsection{Continuous Subcutaneous Hydrocortisone Infusions} (CSHI). Studies of circadian cortisol therapy, using hydrocortisone (HC) infusions or modified-release oral formulations, show that these treatments can better mimic physiological cortisol rhythm and hence result in better GC replacement and ACTH suppression in patients with CAH. Merza and colleagues [35] showed that circadian intravenous infusions of $\mathrm{HC}$ delivered by a programmable pump that replicated the physiological cortisol circadian rhythm reduced ACTH and 17OHP levels in two patients with Addison's disease and two patients with CAH. In another study, continuous subcutaneous HC infusion (CSHI) was evaluated in seven patients with adrenal insufficiency and showed that morning ACTH levels were reduced to near normal levels, the $\mathrm{HC}$ doses were reduced in most patients, and all patients reported satisfaction with this modality [36]. In another recent report, a 4-year therapy with CSHI proved effective and well tolerated in a 14-year-old male with CAH. CSHI treatment produced rapid changes in CAH control and a $50 \%$ reduction in the daily $\mathrm{HC}$ dose within the first 3 months. In addition, the patient demonstrated normal adrenal androgen production and a normal progression through puberty [37].

These reports hold promise for significant benefits of CSHI that include: (1) good adrenal androgen suppression with decreased doses of glucocorticoid and (2) better management of stress and illness because of the pumps capacity to provide boluses readily and increased overall daily hydrocortisone dosing. Hydrocortisone infusions, however, are impractical for many patients and they pose the risk of site and pump failures. Development of oral modified-release formulations of hydrocortisone may be a more practical solution.

3.2. Dual-Timed/Sustained Release Formulations of HC. Although studies evaluating various GC preparations and their timing of administration have been ongoing for years, no clear-cut regimen has proved universally superior in 
children with CAH. Two GC preparations that exploit the pharmacokinetic peak of a once daily, dual-timed HC in order to mimic the diurnal variation peak of ACTH $[38,39]$ and, in turn, facilitate more physiologic delivery are under evaluation. Chronocort, a once daily, dual-timed, sustained oral release HC appears to be promising. Johannsson and colleagues [40] reported a peak cortisol level whose onset is at one hour after oral intake with peak duration of approximately six hours, after that time cortisol levels decreased to a steady state for the remainder of the day. Chronocort was studied in an open label cross-over manner and compared with standard Cortef dosing in the control of CAH [38]. A single oral dose of Chronocort at 2200 compared to standard three daily doses of Cortef (with a higher evening dose of Cortef) showed that the Cortef regimen resulted in three peaks, whereas a single peak at 0600 occurred with Chronocort. 17OHP levels, androstenedione, and ACTH levels were all lower during this period with Chronocort compared to Cortef. However, afternoon "androgen control" was superior with Cortef because HC levels with Chronocort waned.

A second sustained preparation is that of Duocort, whose peak concentration is reached within one hour after intake. Consequently, the use of Duocort to suppress the morning ACTH and subsequent androgen surge in $\mathrm{CAH}$ would require taking the medication in the middle of the night. For children, this would be problematic and will result in decreased compliance.

These new drug-delivery technologies have a significant potential to improve and simplify GC replacement therapy by being more effective, having fewer adverse effects, and improving compliance. Both long-term efficacy and safety of these approaches needs to be established.

\section{4. "Rescue" Strategies}

When children with CAH are short and/or have a predicted adult height (PAH) that is significantly below that of their mid-parental target height (MPH), such that significant adult short stature is expected (e.g., as assessed by a markedly advanced bone age), measures beyond standard therapy are sometimes employed for the physical and psychosocial wellbeing of the child. Often, such strategies rely on experience in other conditions such as precious puberty and McCune Albright syndrome in which stature has been compromised due to an advanced bone age driven by excessive androgens and/or estrogens and the resultant premature epiphyseal maturation. Moreover, chronically elevated adrenal androgens in children with CAH often associated with late onset of therapy or poor compliance can result in early puberty due to early maturation of the HPG axis [41].

4.1. GnRH Agonists with or without Growth Hormone (GH). As with central precocious puberty, the use of $\mathrm{GnRH}$ (gonadotropin releasing hormone agonists), alone or in combination with $\mathrm{GH}$, has been shown to improve $\mathrm{PAH}$ [42-45]. The central precocity accompanying CAH has been shown to respond to GnRH agonists alone as well as in combination with GH $[14,41,46-48]$. While effective in stalling central puberty, growth velocity often decreases upon initiation of GnRH agonist therapy, because it suppresses the effects of sex steroids on linear growth. GH-induced improvement in growth velocity occurs in central precocious puberty as well as in CAH [43, 49]. Quintos et al. [14] reported that GH treatment alone $(n=12)$ or in combination with leuprolide acetate $(n=8)$, a GnRH agonist, improved growth velocity after $1(5 \pm 1.9$ to $7.8 \pm$ $1.6 \mathrm{~cm} / \mathrm{yr})$ and $2(6 \pm 1.6 \mathrm{~cm} / \mathrm{yr})$ years of treatment. A similar improvement in the height SD score for bone age was found in the treatment groups. Lin-Su et al. [47] demonstrated, in a subsequent trial in which fourteen children with $\mathrm{CAH}$ were followed to final adult height, that combination treatment with leuprolide acetate and GH can result in an improved final adult height by approximately $1 \mathrm{SD}$ compared to matched control children who received standard therapy. The effect of these agents, and their duration of use on both the pubertal growth spurt and on bone accretion/peak bone mineral density are areas that require more study in children with $\mathrm{CAH}$.

4.2. Antiandrogens. Blockade of excess androgen production and/or their action is an essential component of $\mathrm{CAH}$ management. The aforementioned strategies have targeted attenuation of adrenal androgen production through manipulation of physiologic feedback loops involving GCs and the hypothalamus and pituitary corticotroph. An alternative approach is to suppress the adrenals less rigidly and to address directly androgen synthesis or actions by using agents that alter (1) synthesis of androgens, (2) conversion of testosterone to its more active metabolites, (3) aromatization of androgens to estrogens, (4) androgen receptor action, and (5) estrogen receptor action.

4.2.1. Inhibitors of Adrenal Androgen Synthesis. Of the adrenal androgen synthesis inhibitors, ketoconazole has been the most widely studied [50]. An azole antifungal drug, ketoconazole at high doses is capable of lowering both testosterone and DHEA (dihydroepiandosterone) by inhibiting the cholesterol side chain cleavage enzyme, 17$\alpha$ hydroxylase, and 17, 20 lyase. While effective in lowering adrenal androgen production, the use of ketoconazole in clinical practice is complicated with its dose-limiting side effects such as fatigue, neurotoxicity, hepatotoxicity, and nausea. Its absorption is erratic and it can interfere with the P450-dependent metabolism of many drugs. In addition, (although not critical to patients with $\mathrm{CAH}$ ) ketoconazole can reduce cortisol synthesis sufficient to necessitate the need for corticosteroid replacement in most patients [51]. Ketoconazole, in more modest doses used for other indications in children, has a relatively benign side-effect profile. However, the dose to suppress adrenal steroid synthesis would be higher and require close monitoring for severe side effects such as hepatotoxicity. Nevertheless, the use of ketoconazole as an adjuvant therapy in $\mathrm{CAH}$ warrants investigation. 
Abiraterone acetate is an orally available, potent, selective, high affinity, irreversible inhibitor of the $17 \alpha$ hydroxylase and C17, 20-lyase (CYP450c17) enzymes [52]. Abiraterone acetate is approximately six to seven times more potent in inhibiting CYP450c17 than ketoconazole [53]. Preclinical and phase I studies in patients with prostate cancer showed that abiraterone effectively suppresses testosterone production in the adrenal gland, and doses of up to $2000 \mathrm{mg} / \mathrm{d}$ were tolerated [54]. Adverse effects (e.g., hypertension, edema, and hypokalemia) associated with abiraterone use are related to the increased production of nonandrogenic steroids as a result of downstream defect on mineralocorticoid secretion created by inhibition of $17 \alpha$-hydroxylase activity [55]. Although such an enzymatic blockade could be problematic in a number of conditions, it should not be a clinically significant problem in patients with classical 21-hydroxylase deficiency because aldosterone synthesis is already impaired. Abiraterone is a promising agent for the management of $\mathrm{CAH}$, but it requires studies of safety and efficacy in children with CAH.

\subsubsection{Androgen Receptor Antagonists. Flutamide, an} androgen-receptor blocker, has been used to treat children with $\mathrm{CAH}$ as part of a four-drug regimen, including testolactone (an aromatase inhibitor), low-dose hydrocortisone, and fludrocortisone. Short-term results are encouraging and showed improved control of height velocity and bone maturation at reduced glucocorticoid dosage [56].

More potent antiandrogens are now available that are in use for the treatment of prostate cancer. Nilutamide, a derivative of flutamide, has pharmacokinetic properties allowing once-daily dosing. Bicalutamide, also derived from flutamide, has two-times increased affinity for the androgen receptor, as compared with flutamide and nilutamide, a longer half-life (one week), and significantly decreased toxicity, most notably in hepatotoxicity. Both nilutamide and bicalutamide have been used effectively in the treatment of prostate cancer $[57,58]$ and have potential in the management of $\mathrm{CAH}$, although the safety and efficacy in the treatment of $\mathrm{CAH}$ is not known.

MDV3100 is the most recently developed antiandrogen agent. It binds androgen receptors with an eightfold higher affinity than does bicalutamide. While other antiandrogens show androgen-receptor agonist properties under some experiment conditions, MDV3100 appears to be a true androgen-receptor antagonist because it both impairs androgen receptor nuclear translocation and blocks DNA binding without apparent agonist properties. The phase 1/2 trials of MDV3100 in patients with prostate cancer show promising results [50]. Again, the role in the management of CAH has yet to be studied.

4.2.3. 5- $\alpha$ Reductase Inhibitors. Inhibitors of the enzyme 5$\alpha$ reductase include finasteride and dutasteride [59]. They block the conversion of testosterone to its active form, dihydrotestosterone (DHT). 5- $\alpha$ reductase inhibitors reduce androgen action on peripheral tissues and may have a role in alleviating the consequences of hyperandrogenism in patients with CAH. These drugs, however, are contraindicated in females of child-bearing age due to their capacity to cross the placenta and induce ambiguous genitalia in the fetus.

4.3. Aromatase Inhibitors (AIs). Aromatase Inhibitors (AIs) act by inhibiting $\mathrm{P} 450$ aromatase, the enzyme that catalyzes the aromatization of $\mathrm{C} 19$ androgens (androstenedione, testosterone) to C18 estrogens (estrone, estradiol). The initial uses for AIs included estrogen-dependent breast cancer [60] and gynecomastia [61]. The expansion of AI use to other conditions has evolved with the development of selective inhibitors of aromatase. The capacity of AIs to decrease estrogen, as well as their effect on the maturation of growth plates, led to the study of the capacity of AIs to prolong linear growth in children with short stature of a variety of etiologies, including $\mathrm{CAH}[62,63]$.

Evidence for the efficacy began with investigation of the nonselective first generation AI, testolactone with positive effects on growth, and PAH in male central precocity (reviewed in [64]). Examination of testolactone therapy in girls with McCune Albright syndrome also showed an improved PAH [65]. Moreover, a study of testolactone in $\mathrm{CAH}$ suggested a positive effect when used in conjunction with an androgen receptor antagonist although three-timedaily dosing proved a hindrance with compliance $[56,66]$. After 2 years, the group that is receiving the experimental treatment regimen had elevated blood androgen levels, but linear growth rate and bone maturation were normal. No significant long-term adverse effects were seen.

Third generation AIs appear to be better tolerated and require only once-daily dosing. Selective third-generation AIs have been used in several short stature conditions, including constitutional delay of growth and puberty [6769], idiopathic short stature, and growth hormone deficiency $[70,71]$. These studies reported that treatment with the AIs letrozole or anastrozole result in improved PAH. The role of these selective AIs warrants controlled longer-term studies in $\mathrm{CAH}$. Further studies of AIs also are warranted in conditions more comparable to $\mathrm{CAH}$ such as central precocious puberty and in gonadotropin-independent precocity, such as in McCune Albright syndrome. As in $\mathrm{CAH}$, these disorders are associated with advancement in bone age (BA) that truncates the time of linear growth and leads to diminished adult stature. A significant goal of AI therapy is to permit a child's chronologic age (CA) to "catch-up" with their BA, such that $\mathrm{PAH}$ is improved [64, 72].

Study of anastrozole in male rats showed an increase in testosterone and decrease in estrogen levels, and an elevation in FSH is likely due to diminished E2 levels. Inhibin B showed no significant change in the rats and spermatogenesis appeared grossly normal [73]. In contrast, in a study of boys with delayed puberty, letrozole resulted in increased LH concentrations and LH pulse amplitude [67]. Dunkel [62] reported no adverse effects on testicular size or inhibin $\mathrm{B}$ levels in boys. The rise in $\mathrm{LH}$, in addition to elevation in testosterone levels, has raised the theoretical concern that letrozole may result in a PCOS-like picture in girls. In 
contrast, the use of AIs is currently under investigation to improve fertility in women with PCOS [74]. The potential teratogenic effects of AIs are, however, unknown $[75,76]$.

The consensus statement by Lawson Wilkins Pediatric Endocrine Society [77] outlined the following concerns on the use of AIs in short stature: (1) all of the data derived from interventions are limited to male patients; (2) only two randomized, double-blinded, placebo-controlled trials were performed, and relatively small number of subjects were treated with AIs; (3) very few patients have been followed to near-adult height, and adult heights from the controlled trials are not available; (4) short-term safety data are reassuring; however, long-term data are lacking. Therefore, AIs are not recommended to be used in females. Long-term studies addressing concerns on their efficacy and safety in both prepubertal and pubertal boys and girls are needed before AI use becomes more widespread.

4.4. Estrogen Receptor Blockers. Estrogen receptor blockers, like aromatase inhibitors, may have a place in the management of $\mathrm{CAH}$ with the goal of delaying androgen-induced rapid skeletal maturation. Many selective estrogen receptor modulators (SERMs) are available. Triphenylethylenes (Tamoxifen, Droloxifene, Idoxifene, Toremifene, and Ospemifene), Benzothiophenes (Raloxiphene, Arzoxifene), and Benzopyrans (Ormeloxifene, levormeloxifene) are effective in blocking estrogen action in breast cancer but have agonistic actions in other tissues including skeletal system [78, 79]. Although their effect on skeletal maturation has not been studied, it is likely that those agents will have no or little effect in delaying bone age maturation. Fulvestrant, the only steroidal antiestrogen, is unique among this category of drugs in that it is a powerful antiestrogen that binds with high affinity to the estrogen receptor but initiates no apparent estrogen agonist activity $[80,81]$. As might be expected, therefore, fulvestrant has been reported to block the estradiol-accelerated skeletal maturation in prepubertal mice [82]. Although its effect on compromising the androgen-accelerated skeletal maturation in the same model was mild [83], fulvestrant seems to be the best candidate among estrogen receptor blockers to prevent rapid androgen-induced acceleration in skeletal maturation in children with $\mathrm{CAH}$.

\section{Bilateral Adrenalectomy}

The rationale for bilateral adrenalectomy in patients with $\mathrm{CAH}$ is similar to other conditions with hormonal overproduction such as hyperthyroidism, acromegaly, hyperprolactinoma, primary hyperaldosteronism, or Cushing's disease in which the hyperfunctioning endocrine organ is removed, and a replacement therapy is started for the resulting hormonal deficiency. In CAH, bilateral adrenalectomy aims to eliminate androgen excess. Other supportive arguments for adrenalectomy are the observations that the management of adrenal insufficiency is less problematic compared to $\mathrm{CAH}$ because lower GC doses are necessary, and saltlosing crisis are less likely. Potential problems with bilateral adrenalectomy include surgical risk and higher risk of adrenal crisis because the majority of patients with $\mathrm{CAH}$ make some endogenous cortisol and aldosterone, potential reduction in ability to respond to stress due to epinephrine deficiency resulting from removal of the adrenal medulla and the potential for Nelson syndrome and adrenal rest tumors if ACTH suppression is not maintained.

Experience with bilateral adrenalectomy in $\mathrm{CAH}$ is limited to relatively small case series and individual case reports. Van Wyk and Ritzen [84] reported follow-up studies in 18 patients who underwent bilateral adrenalectomy for $\mathrm{CAH}$. A total follow-up of 90 patient-years was available and showed that adrenalectomy is a safe procedure in $\mathrm{CAH}$ patients with a good quality of life and health benefits. Signs of androgen excess decreased with much lower doses of glucocorticoid, and obesity was a less common problem. No serious peri- or postoperative morbidity was reported. While most patients had high ACTH levels and hyperpigmentation initially after adrenalectomy, particularly when the $\mathrm{HC}$ dose was reduced to $<10 \mathrm{mg} / \mathrm{m}^{2}$, adequate dose adjustment solved this problem. Adrenal rest tumor was found in one case, but eight patients had high postoperative elevations of steroid precursors suggesting the presence of adrenal rest tumors. Since this initial report more cases have been documented with similar results including its use to successfully treat infertility in two females with CAH [8587]. Laparoscopic adrenalectomy has reduced perioperative morbidity; however, adrenal rest tumors and corticotrophin hypersecretion in association with a pituitary microadenoma have been reported [88]. In contrast to legitimate concerns, no problems with epinephrine deficiency are reported and may be explained by the findings that patients with $\mathrm{CAH}$ on GC replacement already have greatly reduced secretion of epinephrine [89].

In addition to its use in patients who are intractable to conventional treatment, bilateral adrenalectomy as a "prophylactic" measure in young children with double null mutations of their CYP-21 gene is under evaluation. The rationale is to prevent potential virilization due to inadequate suppression of androgens and/or iatrogenic glucocorticoid excess before they occur in severe cases of CAH. Two patients underwent prophylactic adrenalectomy younger than 5 years of age. The youngest patient who was adrenalectomized at 16 months had two episodes of hypoglycemia on low dosage of $\mathrm{HC}\left(8 \mathrm{mg} / \mathrm{m}^{2}\right)$, which did not recur after HC dosage was increased $\left(11-13 \mathrm{mg} / \mathrm{m}^{2}\right)$ throughout her 6-year follow-up after adrenalectomy. The first patient who had prophylactic adrenalectomy at 3 years of age is now 16 years old. She has reached her midparental height and has normal menses and no signs of hyperandrogenism. She, however, continues to have elevated ACTH levels while on replacement dose of glucocorticoid and mineralocorticoid [90].

Bilateral adrenalectomy appears to be a safe and efficacious method of managing patients with severe forms of CAH. Long-term studies comparing this approach with other treatment modalities, however, are lacking. Undoubtedly, adrenalectomized patients should be monitored closely with meticulous management of glucocorticoid and mineralocorticoid replacement and prompt institution of stress 
dosages at the onset of illness. Prophylactic adrenalectomy of young patients may be a viable option in the future if its longterm safety is established but currently should be limited to academic centers with established research protocols.

\section{Gene Therapy}

As other disorders caused by a single gene defect, gene therapy is theoretically possible for all forms of CAH. The development of gene therapy requires an animal model to test the strategy, and a specific, effective, and safe vector to deliver the gene. Both are available for 21-hydroxylase deficiency. The mouse strain $\mathrm{H}-2 \mathrm{aw} 18$, a recombinant mouse line that has a deletion spanning the $\mathrm{C} 4$ gene and one of the two 21-hydroxylase gene, shows typical characteristics of 21-hydroxylase deficiency. Introducing a recombinant DNA fragment containing the murine genomic gene for 21hydroxylase rescued the lethal mutation and showed that this mouse line is a valid model to study gene therapy [91]. Adenoviruses have selective adrenotropism in animals making them a good vector for gene therapy [92, 93]. Indeed, intra-adrenal injection of adenoviral vector encoding the 21 hydroxylase gene has restored the impaired adrenocortical function in these 21-hydroxylase deficient mice [94], and bovine adrenocortical cells have shown functional and morphological changes in the adrenal cortex after transfection with recombinant adenoviruses [95]. The experience with adenoviruses to target 21-hydroxylase to the adrenal cells is encouraging, but overall safety and specificity in targeting the adrenal gland remain unclear. There may be a need to develop new vectors (viral or non-viral) to improve the specificity and efficiency of gene transfer in adrenal gland and to ensure long-term DNA integration. In recent years, other recombinant viruses such as retrovirus, lentivirus, adenoassociated virus, and herpes simplex virus have been widely utilized as vectors for gene transfer. Nonviral gene delivery methods that use synthetic or natural compounds or physical forces to deliver DNA to a cell have become available. While gene therapy is likely to become an option for the treatment of CAH with these advances, the research specific to the gene therapy in $\mathrm{CAH}$ appears to be sparse.

\section{Stem Cells and CAH}

Adult stem cells are derived from specific tissues and have been studied in many venues, particularly that of the hematopoietic system. Limitations of adult stem cells include (1) lack of pluripotency, (2) difficulty to maintain in vitro, and (3) HLA-limitations for transplantation, thus requiring concomitant immunosuppression [96]. Studies using marrow-derived mesenchymal stem cells (MSCs) have provided an additional avenue in that they can be harvested from adults yet are still considered pluripotent [97]. More recent studies have suggested general methods for preparation of induced pluripotent stem cells (IPSCs) from other somatic cell lineages [98]. Note that any cells that are harvested from patients with $\mathrm{CAH}$, either MSCs or IPSCs, could be used as allografts (avoiding issues with HLA compatibility) but would still harbor a genetic deficiency in steroidogenesis and thus would only be useful as cellular vectors for gene therapy. Despite this, use of adult stem cells benefits from a longer track record of investigation and also circumvents ongoing political obstacles regarding the use of fetal tissue.

In contrast, embryonic stem cells (ESCs) provide an approach that could bypass many of the restrictions of adult stem cells [96]. ESCs obtained during the blastocyst stage are logistically easier to maintain and cultivate in vitro and can remain for a longer period in the pluriopotent stage. In principal, ESCs could be triggered to differentiate into regulated, steroidogenic tissue using protocols derived from adult stem cell studies [99]. However, as with adult tissue transplants, HLA-matching is required with potential for graft rejection and necessitates immunosuppressive agents. The next generation of ESCs, however, is those that are HLA matched and, therefore, bypass immunosuppressive regimens after transplantation.

Yazawa et al. [97] showed that human MSCs transfected with SF-1, necessary for both gonadal and adrenal steroidogenesis, differentiated into GC-producing (versus testosterone-producing) cells when transplanted into murine testis. Gondo et al. [100] also used SF-1 to produce steroidogenic cells from MSCs; moreover, the cells were responsive to stimulation by ACTH. The authors then reported that a differential hormonal profile was synthesized by transformed stem cells derived from bone marrow than from those derived from adipose stem cells, suggesting that site of stem cell origin is important in determining which steroidogenic pathways can be induced [101].

An additional approach is that of Hammer and colleagues, who have characterized a subpopulation of adrenal cells that are typically undifferentiated or "dormant" [102, 103]. Stimulation of these cells to differentiate into mature adrenal cells under various physiologic or pathophysiologic conditions may be possible, and studies aimed at harvesting this quiescent population for both differentiation and/or regeneration of adrenal tissue are targets for both $\mathrm{CAH}$ and for adrenal insufficiency of other etiologies [101-103].

The potential use of stem cells to provide functional adrenal cortical tissue would, if realized, represent a cure for CAH. A key to the success of such an approach would be to provide adrenal tissue that responded in a physiological fashion to both positive and negative regulators.

\section{Conclusion}

Although introduction of glucocorticoid and mineralocorticoid treatment markedly decreased mortality and morbidity of patients with $\mathrm{CAH}$, management of $\mathrm{CAH}$ remains challenging. Clinicians are often frustrated by the difficulties in maintaining satisfactory adrenal suppression without producing an unacceptable degree of hypercortisolism. Shortened adult stature and progressive obesity are common. Novel treatments with great potential to improve outcomes are available, but their use is hampered by the lack of studies in the $\mathrm{CAH}$ population. Most clinical trials to date 
suffer from relatively small sample sizes and/or retrospective approach. Prospective, randomized, placebo-controlled multicenter trials are required to interpret the appropriate use of these promising agents in children with CAH. Unfortunately, funding is sparse, and the pharmaceutical industry has little interest in investing such a small population of patients. It is critical, therefore, that pediatric endocrinologists, patients, and their families, in addition to advocacy groups, continue to promote collaborative efforts to permit such research endeavors.

\section{Abbreviations}

ACTH: Adrenocorticotropic hormone

AI: Aromatase Inhibitor

CAH: Congenital Adrenal Hyperplasia

CRH: Corticotropin Releasing Hormone

GC: Glucocorticoid

GnRH: Gonadotropin Releasing Hormone

HC: Hydrocortisone.

\section{References}

[1] K. J. Loechner, R. J. Knox, J. T. McLaughlin, and K. Dunlap, "Dexamethasone-mediated inhibition of calcium transients and ACTH release in a pituitary cell line (AtT-20)," Steroids, vol. 64, no. 6, pp. 404-412, 1999.

[2] L. Sherwood, Fundamentals of Physiology: A Human Perspective, Thomson Brooks/Cole, Sydney, Australia, 2006.

[3] A. T. T. Nguyen, J. J. Brown, and G. L. Warne, "Growth in congenital adrenal hyperplasia," Indian Journal of Pediatrics, vol. 73, no. 1, pp. 89-93, 2006.

[4] G. B. Cutler Jr. and L. Laue, "Congenital adrenal hyperplasia due to 21-hydroxylase deficiency," New England Journal of Medicine, vol. 323, no. 26, pp. 1806-1813, 1990.

[5] F. J. Cameron, B. Kaymakci, E. A. Byrt, P. R. Ebeling, G. L. Warne, and J. D. Wark, "Bone mineral density and body composition in congenital adrenal hyperplasia," Journal of Clinical Endocrinology and Metabolism, vol. 80, no. 7, pp. 2238-2243, 1995.

[6] R. E. Cornean, P. C. Hindmarsh, and C. G. D. Brook, "Obesity in 21-hydroxylase deficient patients," Archives of Disease in Childhood, vol. 78, no. 3, pp. 261-263, 1998.

[7] K. Hagenfeldt, E. M. Ritzen, H. Ringertz, J. Helleday, and K. Carlstrom, "Bone mass and body composition of adult women with congenital virilizing 21-hydroxylase deficiency after glucocorticoid treatment since infancy," European Journal of Endocrinology, vol. 143, no. 5, pp. 667-671, 2000.

[8] J. Jääskeläinen and R. Voutilainen, "Bone mineral density in relation to glucocorticoid substitution therapy in adult patients with 21-hydroxylase deficiency," Clinical Endocrinology, vol. 45, no. 6, pp. 707-713, 1996.

[9] S. A. Warinner, D. Zimmerman, G. B. Thompson, and C. S. Grant, "Study of three patients with congenital adrenal hyperplasia treated by bilateral adrenalectomy," World Journal of Surgery, vol. 24, no. 11, pp. 1347-1352, 2000.

[10] K. J. Loechner, S. Patel, and J. T. McLaughlin, "Decreased bone mineral density and vertebral compression fractures in a young adult male with 21-hydroxylase deficiency congenital adrenal hyperplasia $(\mathrm{CAH})$ : is $\mathrm{CAH}$ an unrecognized population at risk for glucocorticoid-induced osteoporosis?" Journal of Pediatric Endocrinology and Metabolism, vol. 23, no. 1-2, pp. 179-187, 2010.

[11] R. Rasat, E. A. Espiner, and G. D. Abbott, "Growth patterns and outcomes in congenital adrenal hyperplasia; effect of chronic treatment regimens," New Zealand Medical Journal, vol. 108, no. 1005, pp. 311-314, 1995.

[12] R. Girgis and J. S. D. Winter, "The effects of glucocorticoid replacement therapy on growth, bone mineral density, and bone turnover markers in children with congenital adrenal hyperplasia," Journal of Clinical Endocrinology and Metabolism, vol. 82, no. 12, pp. 3926-3929, 1997.

[13] I. N. Silva, D. F. Oliveira Júnior, C. J. R. Simal, M. B. Viana, and A. J. Chagas, "Morning steroid profile in children with congenital adrenal hyperplasia under different hydrocortisone schedules," Indian Journal of Pediatrics, vol. 61, no. 4, pp. 341-346, 1994.

[14] J. B. Quintos, M. G. Vogiatzi, M. D. Harbison, and M. I. New, "Growth hormone therapy alone or in combination with gonadotropin-releasing hormone analog therapy to improve the height deficit in children with congenital adrenal hyperplasia," Journal of Clinical Endocrinology \& Metabolism, vol. 86, no. 4, pp. 1511-1517, 2001.

[15] D. P. Merke, S. R. Bornstein, N. A. Avila, and G. P. Chrousos, "NIH conference: future directions in the study and management of congenital adrenal hyperplasia due to 21-hydroxylase deficiency," Annals of Internal Medicine, vol. 136, no. 4, pp. 320-334, 2002.

[16] E. Zoumakis, D. K. Grammatopoulos, and G. P. Chrousos, "Corticotropin-releasing hormone receptor antagonists: an update," Endocrine Development, vol. 17, pp. 36-43, 2010.

[17] S. R. Bornstein, E. L. Webster, D. J. Torpy et al., "Chronic effects of a nonpeptide corticotropin-releasing hormone type I receptor antagonist on pituitary-adrenal function, body weight, and metabolic regulation," Endocrinology, vol. 139, no. 4, pp. 1546-1555, 1998.

[18] T. Deak, K. T. Nguyen, A. L. Ehrlich et al., "The impact of the nonpeptide corticotropin-releasing hormone antagonist antalarmin on behavioral and endocrine responses to stress," Endocrinology, vol. 140, no. 1, pp. 79-86, 1999.

[19] J. Rivier, J. Gulyas, A. Corrigan et al., "Astressin analogues (corticotropin-releasing factor antagonists) with extended duration of action in the rat," Journal of Medicinal Chemistry, vol. 41, no. 25, pp. 5012-5019, 1998.

[20] K. Yayou, M. Nakamura, and S. Ito, "Effects of AVP V1a and $\mathrm{CRH}$ receptor antagonist on psychological stress responses to frustrating condition in sheep," Journal of Veterinary Medical Science, vol. 71, no. 4, pp. 431-439, 2009.

[21] F. Holsboer and M. Ising, "Central CRH system in depression and anxiety-evidence from clinical studies with CRH1 receptor antagonists," European Journal of Pharmacology, vol. 583, no. 2-3, pp. 350-357, 2008.

[22] K. G. Mountjoy, L. S. Robbins, M. T. Mortrud, and R. D. Cone, "The cloning of a family of genes that encode the melanocortin receptors," Science, vol. 257, no. 5074, pp. 1248-1251, 1992.

[23] J. B. Tatro, "Receptor biology of the melanocortins, a family of neuroimmunomodulatory peptides," NeuroImmunoModulation, vol. 3, no. 5, pp. 259-284, 1997.

[24] J. Voisey, L. Caroll, and A. van Daal, "Melanocortins and their receptors and antagonists," Current Drug Targets, vol. 4, no. 7, pp. 586-597, 2003.

[25] V. Kyriazopoulou, "Glucocorticoid replacement therapy in patients with Addison's disease," Expert Opinion on Pharmacotherapy, vol. 8, no. 6, pp. 725-729, 2007. 
[26] Adrenal Insufficiency and Addison's Disease, NIH Information Service Publication no. 09-3054, National Endocrine and Metabolic Diseases, 2009.

[27] D. P. Merke and S. R. Bornstein, "Congenital adrenal hyperplasia," Lancet, vol. 365, no. 9477, pp. 2125-2136, 2005.

[28] K. J. Loechner, R. M. Kream, and K. Dunlap, "Calcium currents in a pituitary cell line (AtT-20): differential roles in stimulus-secretion coupling," Endocrinology, vol. 137, no. 4, pp. 1429-1437, 1996.

[29] J. W. Rogan, D. A. Lyszkiewicz, D. Blowey, S. Khattak, G. S. Arbus, and G. Koren, "A randomized prospective crossover trial of amlodipine in pediatric hypertension," Pediatric Nephrology, vol. 14, no. 12, pp. 1083-1087, 2000.

[30] J. T. Flynn and D. A. Pasko, "Calcium channel blockers: pharmacology and place in therapy of pediatric hypertension," Pediatric Nephrology, vol. 15, no. 3-4, pp. 302-316, 2000.

[31] L. De Marinis, A. Mancini, and S. Minnielli, "Calcium antagonists and hormone release. V. Effects of a calciumantagonist (verapamil) on pituitary hormone release in hypersecretory states," Hormone Research, vol. 25, no. 1, pp. 5-12, 1987.

[32] K. J. Loechner, R. Schock, and J. T. McLaughlin, “Congenital adrenal hyperplasia (CAH): calcium channels as therapeutic targets," Pediatric Academic Societies. Abstract no. 753061, 2007.

[33] L. A. Casulari, L. A. Naves, P. A. Mello, A. P. Neto, and C. Papadia, "Nelson's syndrome: complete remission with cabergoline but not with bromocriptine or cyproheptadine treatment," Hormone Research, vol. 62, no. 6, pp. 300-305, 2004.

[34] D. E. Schteingart, "Drugs in the medical treatment of Cushing's syndrome," Expert Opinion on Emerging Drugs, vol. 14, no. 4, pp. 661-671, 2009.

[35] Z. Merza, A. Rostami-Hodjegan, A. Memmott et al., "Circadian hydrocortisone infusions in patients with adrenal insufficiency and congenital adrenal hyperplasia," Clinical Endocrinology, vol. 65, no. 1, pp. 45-50, 2006.

[36] K. Løvås and E. S. Husebye, "Continuous subcutaneous hydrocortisone infusion in Addison's disease," European Journal of Endocrinology, vol. 157, no. 1, pp. 109-112, 2007.

[37] S. M. Bryan, J. W. Honour, and P. C. Hindmarsh, "Management of altered hydrocortisone pharmacokinetics in a boy with congenital adrenal hyperplasia using a continuous subcutaneous hydrocortisone infusion," Journal of Clinical Endocrinology and Metabolism, vol. 94, no. 9, pp. 3477-3480, 2009.

[38] S. Verma, C. Vanryzin, N. Sinaii, et al., "A pharmacokinetic and pharmacodynamic study of delayed- and extendedrelease hydrocortisone (Chronocort) versus conventional hydrocortisone (Cortef) in the treatment of congenital adrenal hyperplasia," Clinical Endocrinology, vol. 68, no. 1, pp. 34-45, 2009.

[39] M.-L. Nunes and A. Tabarin, "News for adrenal insufficiency," Annales d'Endocrinologie, vol. 69, supplement 1, pp. S44-S52, 2008.

[40] G. Johannsson, R. Bergthorsdottir, A. G. Nilsson, H. Lennernas, T. Hedner, and S. Skrtic, "Improving glucocorticoid replacement therapy using a novel modified-release hydrocortisone tablet: a pharmacokinetic study," European Journal of Endocrinology, vol. 161, no. 1, pp. 119-130, 2009.

[41] A. T. Soliman, M. AlLamki, I. AlSalmi, and M. Asfour, "Congenital adrenal hyperplasia complicated by central precocious puberty: linear growth during infancy and treatment with gonadotropin- releasing hormone analog," Metabolism, vol. 46, no. 5, pp. 513-517, 1997.

[42] M. S. Kappy, T. Stuart, and A. Perelman, "Efficacy of leuprolide therapy in children with central precocious puberty," American Journal of Diseases of Children, vol. 142, no. 10, pp. 1061-1064, 1988.

[43] R. D. Clemons, M. S. Kappy, T. E. Stuart, A. H. Perelman, and F. T. Hoekstra, "Long-term effectiveness of depot gonadotropin-releasing hormone analogue in the treatment of children with central precocious puberty," American Journal of Diseases of Children, vol. 147, no. 6, pp. 653-657, 1993.

[44] P. A. Lee, "The effects of manipulation of puberty on growth," Hormone Research, vol. 60, supplement 1, pp. 60-67, 2003.

[45] P. A. Lee, "Use of GnRH agonists in GH-deficient patients: arguments for and against. The case for GnRH agonists in GH-deficient patients," Pediatric Endocrinology Reviews, vol. 5, no. supplement 2, pp. 744-749, 2008.

[46] T. Tanaka, M. Satoh, T. Yasunaga, R. Horikawa, A. Tanae, and I. Hibi, "GH and GnRH analog treatment in children who enter puberty at short stature," Journal of Pediatric Endocrinology and Metabolism, vol. 10, no. 6, pp. 623-628, 1997.

[47] K. Lin-Su, M. G. Vogiatzi, I. Marshall et al., "Treatment with growth hormone and luteinizing hormone releasing hormone analog improves final adult height in children with congenital adrenal hyperplasia," Journal of Clinical Endocrinology and Metabolism, vol. 90, no. 6, pp. 3318-3325, 2005.

[48] L. J. Chalmers, L. Casas, M. I. New, and P. R. Blackett, "Prolongation of growth by treatment of 11-hydroxylase deficiency with depot-leuprolide, growth hormone, hydrocortisone," Journal of Pediatric Endocrinology and Metabolism, vol. 19, no. 10, pp. 1251-1255, 2006.

[49] J. Bell, K. L. Parker, R. D. Swinford, A. R. Hoffman, T. Maneatis, and B. Lippe, "Long-term safety of recombinant human growth hormone in children," Journal of Clinical Endocrinology and Metabolism, vol. 95, no. 1, pp. 167-177, 2010.

[50] A. C. Hsieh and C. J. Ryan, "Novel concepts in androgen receptor blockade," Cancer Journal, vol. 14, no. 1, pp. 11-14, 2008.

[51] Y. Chen, N. J. Clegg, and H. I. Scher, "Anti-androgens and androgen-depleting therapies in prostate cancer: new agents for an established target," The Lancet Oncology, vol. 10, no. 10, pp. 981-991, 2009.

[52] S. E. Barrie, G. A. Potter, P. M. Goddard, B. P. Haynes, M. Dowsett, and M. Jarman, "Pharmacology of novel steroidal inhibitors of cytochrome $P 450_{17 \alpha}$ (17 $\alpha$-hydroxylase/C17-20 lyase)," Journal of Steroid Biochemistry and Molecular Biology, vol. 50, no. 5-6, pp. 267-273, 1994.

[53] C. Ryan, MR Smith, and J. E. Rosenberg, "Impact of prior ketoconazole therapy on response proportion to abiraterone acetate, a 17-alpha hydroxylase C17, 20-lyase inhibitor in castration resistant prostate cancer (CRPC)," Proceeding of American Society of Clinical Oncology, vol. 26, supplement 15, p. 5018, 2008.

[54] C. J. Ryan, M. R. Smith, L. Fong et al., "Phase I clinical trial of the CYP17 inhibitor abiraterone acetate demonstrating clinical activity in patients with castration-resistant prostate cancer who received prior ketoconazole therapy," Journal of Clinical Oncology, vol. 28, no. 9, pp. 1481-1488, 2010. 
[55] D. C. Danila, M. J. Morris, J. S. de Bono, et al., "Phase II multicenter study of abiraterone acetate plus prednisone therapy in patients with docetaxel-treated castration-resistant prostate cancer," Journal of Clinical Oncology, vol. 28, no. 9, pp. 1496-1501, 2010.

[56] D. P. Merke, M. F. Keil, J. V. Jones, J. Fields, S. Hill, and G. B. Cutler Jr., "Flutamide, testolactone, and reduced hydrocortisone dose maintain normal growth velocity and bone maturation despite elevated androgen levels in children with congenital adrenal hyperplasia," Journal of Clinical Endocrinology and Metabolism, vol. 85, no. 3, pp. 1114-1120, 2000.

[57] K. Siddiqui and L. H. Klotz, "Emerging drugs for prostate cancer," Expert Opinion on Emerging Drugs, vol. 14, no. 3, pp. 455-470, 2009.

[58] E. M. Van Allen and C. J. Ryan, "Novel secondary hormonal therapy in advanced prostate cancer: an update," Current Opinion in Urology, vol. 19, no. 3, pp. 315-321, 2009.

[59] A. N. Vis and F. H. Schröder, "Key targets of hormonal treatment of prostate cancer, part 2: the androgen receptor and $5 \alpha$-reductase," BJU International, vol. 104, no. 9, pp. 1191-1197, 2009.

[60] I. Czajka-Oraniec and E. R. Simpson, "Aromatase research and its clinical significance," Endokrynologia Polska, vol. 61, no. 1, pp. 126-134, 2010.

[61] R. J. Santen, H. Brodie, E. R. Simpson, P. K. Siiteri, and A. Brodie, "History of aromatase: saga of an important biological mediator and therapeutic target," Endocrine Reviews, vol. 30, no. 4, pp. 343-375, 2009.

[62] L. Dunkel, "Use of aromatase inhibitors to increase final height," Molecular and Cellular Endocrinology, vol. 255, pp. 207-216, 2006.

[63] O. Eyal, L. Naugolny, and N. Weintrob, "The use of aromatase inhibitors in children," Harefuah, vol. 148, no. 12, pp. 825830, 2009.

[64] E. A. Eugster, "Aromatase inhibitors in precocious puberty: rationale and experience to date," Treatments in Endocrinology, vol. 3, no. 3, pp. 141-151, 2004.

[65] P. P. Feuillan, J. Jones, and G. B. Cutler Jr., "Long term testolactone therapy for precocious puberty in girls with the McCune-Albright syndrome," Journal of Clinical Endocrinology and Metabolism, vol. 77, no. 3, pp. 647-651, 1993.

[66] P. Feuillan, D. Merke, E. W. Leschek, and G. B. Cutler Jr., "Use of aromatase inhibitors in precocious puberty," EndocrineRelated Cancer, vol. 6, no. 2, pp. 303-306, 1999.

[67] S. Wickman, I. Sipilä, C. Ankarberg-Lindgren, E. Norjavaara, and L. Dunkel, "A specific aromatase inhibitor and potential increase in adult height in boys with delayed puberty: a randomised controlled trial," Lancet, vol. 357, no. 9270, pp. 1743-1748, 2001.

[68] S. Wickman, T. Saukkonen, and L. Dunkel, "The role of sex steroids in the regulation of insulin sensitivity and serum lipid concentrations during male puberty: a prospective study with a P450-aromatase inhibitor," European Journal of Endocrinology, vol. 146, no. 3, pp. 339-346, 2002.

[69] M. Hero, S. Wickman, and L. Dunkel, "Treatment with the aromatase inhibitor letrozole during adolescence increases near-final height in boys with constitutional delay of puberty," Clinical Endocrinology, vol. 64, no. 5, pp. 510-513, 2006.

[70] L. Dunkel, "Update on the role of aromatase inhibitors in growth disorders," Hormone Research, vol. 71, supplement 1, pp. 57-63, 2009.
[71] N. Mauras, "Strategies for maximizing growth in puberty in children with short stature," Endocrinology and Metabolism Clinics of North America, vol. 38, no. 3, pp. 613-624, 2009.

[72] D. Damiani and D. Damiani, "Pharmacological management of children with short stature: the role of aromatase inhibitors," Jornal de Pediatria, vol. 83, no. 5, pp. S172-S177, 2007.

[73] K. J. Turner, M. Morley, N. Atanassova, I. D. Swanston, and R. M. Sharpe, "Effect of chronic administration of an aromatase inhibitor to adult male rats on pituitary and testicular function and fertility," Journal of Endocrinology, vol. 164, no. 2, pp. 225-238, 2000.

[74] K. R. Eckmann and D. R. Kockler, "Aromatase inhibitors for ovulation and pregnancy in polycystic ovary syndrome," Annals of Pharmacotherapy, vol. 43, no. 7-8, pp. 1338-1346, 2009.

[75] S. K. Gill, M. Moretti, and G. Koren, "Is the use of letrozole to induce ovulation teratogenic?" Canadian Family Physician, vol. 54, no. 3, pp. 353-354, 2008.

[76] A. Requena, J. Herrero, J. Landeras, et al., "Use of letrozole in assisted reproduction: a systematic review and metaanalysis," Human Reproduction Update, vol. 14, no. 6, pp. 571-582, 2008

[77] D. I. Shulman, G. L. Francis, M. R. Palmert, and E. A. Eugster, "Use of aromatase inhibitors in children and adolescents with disorders of growth and adolescent development," Pediatrics, vol. 121, no. 4, pp. e975-e983, 2008.

[78] W. Shelly, M. W. Draper, V. Krishnan, M. Wong, and R. B. Jaffe, "Selective estrogen receptor modulators: an update on recent clinical findings," Obstetrical and Gynecological Survey, vol. 63, no. 3, pp. 163-181, 2008.

[79] T. Wang, Q. You, F. S.-G. Huang, and H. Xiang, "Recent advances in selective estrogen receptor modulators for breast cancer," Mini-Reviews in Medicinal Chemistry, vol. 9, no. 10, pp. 1191-1201, 2009.

[80] A. U. Buzdar and J. F. R. Robertson, "Fulvestrant: pharmacologic profile versus existing endocrine agents for the treatment of breast cancer," Annals of Pharmacotherapy, vol. 40, no. 9, pp. 1572-1583, 2006.

[81] A. Howell, "Pure oestrogen antagonists for the treatment of advanced breast cancer," Endocrine-Related Cancer, vol. 13, no. 3, pp. 689-706, 2006.

[82] D. F. Gunther, A. S. Calikoglu, and L. E. Underwood, "The effects of the estrogen receptor blocker, Faslodex (ICI $182,780)$, on estrogen-accelerated bone maturation in mice," Pediatric Research, vol. 46, no. 3, pp. 269-273, 1999.

[83] D. F. Gunther, L. E. Underwood, and A. S. Calikoglu, "Androgen-accelerated bone maturation in mice is not attenuated by Faslodex, an estrogen receptor blocker," Bone, vol. 28, no. 4, pp. 410-413, 2001.

[84] J. J. Van Wyk and E. M. Ritzen, "The role of bilateral adrenalectomy in the treatment of congenital adrenal hyperplasia," Journal of Clinical Endocrinology and Metabolism, vol. 88, no. 7, pp. 2993-2998, 2003.

[85] O. A. Castillo, G. Vitagliano, O. Cortes, M. Kerkebe, I. Pinto, and L. Arellano, "Bilateral laparoscopic adrenalectomy," Journal of Endourology, vol. 21, no. 9, pp. 1053-1058, 2007.

[86] C. M. Ogilvie, G. Rumsby, T. Kurzawinski, and G. S. Conway, "Outcome of bilateral adrenalectomy in congenital adrenal hyperplasia: one unit's experience," European Journal of Endocrinology, vol. 154, no. 3, pp. 405-408, 2006.

[87] M. John, S. K. Menon, N. S. Shah, and P. S. Menon, "Congenital adrenal hyperplasia $11 \beta$-hydroxylase deficiency: 
two cases managed with bilateral adrenalectomy," Singapore Medical Journal, vol. 50, no. 2, pp. e68-e70, 2009.

[88] E. Charmandari, G. P. Chrousos, and D. P. Merke, "Adrenocorticotropin hypersecretion and pituitary microadenoma following bilateral adrenalectomy in a patient with classic 21-hydroxylase deficiency," Journal of Pediatric Endocrinology and Metabolism, vol. 18, no. 1, pp. 97-101, 2005.

[89] D. P. Merke, G. P. Chrousos, G. Eisenhofer et al., "Adrenomedullary dysplasia and hypofunction in patients with classic 21-hydroxylase deficiency," New England Journal of Medicine, vol. 343, no. 19, pp. 1362-1368, 2000.

[90] D. F. Gunther, T. P. Bukowski, E. M. Ritzén, A. Wedell, and J. J. Van Wyk, "Prophylactic adrenalectomy of a threeyear-old girl with congenital adrenal hyperplasia: pre- and postoperative studies," Journal of Clinical Endocrinology and Metabolism, vol. 82, no. 10, pp. 3324-3327, 1997.

[91] H. Gotoh, M. Kusakabe, T. Shiroishi, and K. Moriwaki, "Survival of steroid 21-hydroxylase-deficient mice without endogenous corticosteroids after neonatal treatment and genetic rescue by transgenesis as a model system for treatment of congenital adrenal hyperplasia in humans," Endocrinology, vol. 135, no. 4, pp. 1470-1476, 1994.

[92] G. Margolis, L. Kilham, and E. M. Hoenig, "Experimental adenovirus infection of the mouse adrenal gland. I. Light microscopic observation," American Journal of Pathology, vol. 75, no. 2, pp. 363-374, 1974.

[93] E. Stauber and C. Card, "Experimental intraamnionic exposure of bovine fetuses with subgroup 2, type 7 adenovirus," Canadian Journal of Comparative Medicine, vol. 42, no. 4, pp. 466-472, 1978.

[94] T. Tajima, T. Okada, X.-M. Ma, W. J. Ramsey, S. R. Bornstein, and G. Aguilera, "Restoration of adrenal steroidogenesis by adenovirus-mediated transfer of human cytochrome P450 21-hydroxylase into the adrenal gland of 21-hydroxylasedeficient mice," Gene Therapy, vol. 6, no. 11, pp. 1898-1903, 1999.

[95] S. Alesci, W. J. Ramsey, S. R. Bornstein et al., "Adenoviral vectors can impair adrenocortical steroidogenesis: clinical implications for natural infections and gene therapy," Proceedings of the National Academy of Sciences of the United States of America, vol. 99, no. 11, pp. 7484-7489, 2002.

[96] A. C. Brignier and A. M. Gewirtz, "Embryonic and adult stem cell therapy," Journal of Allergy and Clinical Immunology, vol. 125, no. 2, supplement 2, pp. S336-S344, 2010.

[97] T. Yazawa, T. Mizutani, K. Yamada et al., "Differentiation of adult stem cells derived from bone marrow stroma into Leydig or adrenocortical cells," Endocrinology, vol. 147, no. 9, pp. 4104-4111, 2006.

[98] E. Kiskinis and K. Eggan, "Progress toward the clinical application of patient-specific pluripotent stem cells," Journal of Clinical Investigation, vol. 120, no. 1, pp. 51-59, 2010.

[99] R. Müller and C. Lengerke, "Patient-specific pluripotent stem cells: promises and challenges," Nature Reviews Endocrinology, vol. 5, no. 4, pp. 195-203, 2009.

[100] S. Gondo, T. Yanase, T. Okabe et al., "SF-1/Ad4BP transforms primary long-term cultured bone marrow cells into ACTHresponsive steroidogenic cells," Genes to Cells, vol. 9, no. 12, pp. 1239-1247, 2004.

[101] A. C. Kim and G. D. Hammer, "Adrenocortical cells with stem/progenitor cell properties: recent advances," Molecular and Cellular Endocrinology, vol. 265-266, pp. 10-16, 2007.

[102] A. C. Kim, F. M. Barlaskar, J. H. Heaton et al., "In search of adrenocortical stem and progenitor cells," Endocrine Reviews, vol. 30, no. 3, pp. 241-243, 2009.
[103] T. Yanase, S. Gondo, T. Okabe et al., "Differentiation and regeneration of adrenal tissues: an initial step toward regeneration therapy for steroid insufficiency," Endocrine Journal, vol. 53, no. 4, pp. 449-459, 2006. 